\title{
Lawyer Secondary Consultations: improving access to justice: reaching clients otherwise excluded through professional support in a multi-disciplinary practice ${ }^{1}$
}

\author{
Liz Curran \\ Australian National University
}

\begin{abstract}
If people do not know they have rights or legal responsibilities; do not have the confidence to assert them or do not know the pathways to gain access to legal support and advice to action these legal rights, then those legal rights become unrealisable. It is now empirically established that unresolved legal problems result in poorer health and social outcomes. This article explores secondary consultations, where a lawyer gives one-to-one information or advice in a timely and approachable way to non-legal professionals ('trusted intermediaries') likely to have contact with vulnerable and disadvantaged clients, is an effective way of reaching clients who would otherwise not gain help or advice. The thesis for this article is that legal secondary consultations builds capacity and confidence in professionals to identify legal issues so they either support a client or, where appropriate, refer clients who would otherwise not get help because of a range of inhibitors. Legal secondary consultations enable people to identify legal issues which if unidentified or unresolved can impact significantly on their lives. The author draws on findings from recent research in urban, outer urban and rural settings in Australia and on her practical experience of secondary consultations for over a decade.
\end{abstract}

Keywords: human rights, social inclusion, engagement, secondary consultation, legal services, access to justice, multi-disciplinary practice.

I now know that sometimes when the Department says it's a 'no' to my client that they may be wrong and I feel better able to question it as the legal advice shows me a 'no' is often a 'maybe'. (Community health service nurse)

Corresponding author: Liz Curran (liz.curran@anu.edu.au)

The legal system is often alienating and complicated, with many barriers for people experiencing multiple problems with complex issues. Law problem identification, navigation of complex service and legislative arrangements and legal processes can be overwhelming and confusing. Combine this with often-unrelenting pressures of poor health, mental or other disabilities, poverty, addiction and low-level education or limited finances, and the realisation of human rights or finding pathways to resolving problems capable of a legal solution becomes impossible. The author's legal practice experience has demonstrated that many people who experience vulnerability or disadvantage have little awareness of their legal and human rights and very little confidence or wherewithal in actioning them. As this article will show, recent empirical studies provide an evidence

\footnotetext{
${ }^{1}$ Based on a paper presented at the National Conference of Community Legal Centres, Melbourne, 27 August 2015.
} 
base for supporting this practical experience. In Australia, there are notions of 'Equality before the Law' and the 'Rule of Law'. Critical in attaining such notions is identification of rights and an ability and confidence for members of the public to be able to seek advice, help and action the pathways, options and remedies allegedly open to them in legal and social frameworks.

Most people's perception of problems, which may have a legal solution, is limited. Research has also highlighted that many professionals who work with vulnerable and disadvantaged clients are also not aware of the range of problems capable of a legal solution. (Balmer, Pleasence, Buck, \& Walker, 2006). Innovative ways of breaking through gaps in knowledge and poor access to justice are emerging. These involve doing things differently to traditional modes of legal service delivery. Instead of waiting for clients to make appointments, they see lawyers actually going to where the people currently excluded are likely to be and working with professionals to whom people experiencing disadvantage (such as children, people with intellectual and mental problems, or poor housing) might turn.

It is now empirically established that unresolved legal problems result in poorer health and social outcomes (Buck, Pleasance, \& Balmer, 2008; Coumarelos, MacCourt, People, McDonald, Wei, Iriana, \& Ramsey, 2012; Balmer et al., 2006). This article argues that the use of lawyer secondary consultations (SC) in a timely and approachable way to non-legal professionals ('trusted intermediaries') who are likely to have contact with the most vulnerable and disadvantaged clients can be an effective way of reaching clients who might never otherwise gain help or advice.

The article will draw on several related areas of the author's own research and other research where she has an advisory role. It outlines some emerging data and findings in terms how SC can enhance access to justice for clients who are currently unable to access legal help. It examines the value of tailored professional support through the availability of SC and what makes effective SC (Consumer Action Law Centre), barriers to collaboration that explain previous reticence of non-legal professionals to turn to the law (the Loddon Campaspe Family Violence collaborative survey), and Health Justice Partnership research findings around what leads to effective engagement of professionals through use of SC to assist them in their work for those most likely to be excluded from gaining help with problems capable of a legal solution.

Solutions to problems can often emerge through negotiation and availing people of existing mechanisms provided by the law which provide notions of fairness and due process that clients and their professional supporters may often not know exist. Research has shown that may professional see legal problems as limited to traditional areas such as criminal and family law and do not realise that all spheres of social life are government by laws thus presenting many more options (Noone \& Digney, 2010). The author's recent research and advisory work examines service impact and effectiveness on client/patient outcomes of integrated and holistic service delivery where lawyers are co-located in multi-disciplinary practices aiming to better reach people with legal problems. Many of the client/patient problems emerging have not only a legal dimension but also impact on very fundamental human rights such as income security, inadequate or unstable housing, health and so on. The value of SC in improving outcomes and access to justice is emerging as a critical element in engaging clients who would otherwise not gain legal help and other professional supports. This is the focus of this article. This article's discussion also draws on the author's practical experience for a 
decade providing SC in a legal service that was co-located with a health service in a low socioeconomic area in inner Melbourne.

There is very limited literature on SC by legal professionals with non-legal professionals and yet the author's research and advisory evaluation work is demonstrating it is critical in reaching people experiencing disadvantage or vulnerability. This article aims to begin filling this vacuum.

The article's focus is specifically on SC rather than multi-disciplinary practice or collaboration more broadly (this will be discussed in other articles). The article will outline key findings on SC from the author's recent research and research that she has been involved in with an advisory role. These disclose some critical elements for good SC which lead to referrals, client/patient reach and effective collaboration to better assist people with problems, enabling earlier effective interventions before problems escalate or become entrenched and lead to dire outcomes such as eviction or poor health. This article contributes to discussions around effective elements of service delivery using SCs to assist a range of professionals in health and allied health services, in social work and in financial counselling. It also hopes that legal assistance agencies can both celebrate and name what it is that they possibly already do or start to value and count this if they do not already do so.

\section{What are Secondary Consultations?}

In the context of this article, secondary consultations (SC) are defined as where a lawyer offers a non-legal professional (such as a doctor, nurse, youth worker, social worker or financial counsellor) legal information or advice on legal processes for their client through the non-legal professional as an intermediary or assists the professional in their role (such as what happens at court, and how to give evidence or structure reports for a court to provide the required considerations), or on their professional and ethical obligations, or guides the non-legal professional through tricky situations involving their client or their work for clients. It is 'secondary' in that the legal information is provided to the professional intermediary who is already supporting a client and then this intermediary uses this information to assist their client or patient or the information is used to enable the professional to better support the client. The author has presented a paper and written a more detailed article canvassing how the ethical and professional responsibilities of professionals using SC have been managed (forthcoming) and so this is not the focus of this article (Curran, 2016c). Critically, SCs can build capacity in nonlegal professionals likely to come into contact with the most challenging problems or clients unlikely to otherwise seek help from a lawyer, so as to be able to identify or quickly verify with a lawyer that a problem is capable of a legal solution.

SC opens up pathways to the non-legal professional's clients or patients as 'trusted intermediaries' to whom clients turn with an array of problems, which may include legal issues. SC helps the professional to gain the direct guidance (through a short discussion with a lawyer by phone or direct meeting) that they might need to better help their client or check if they can access legal help. This article extracts some key data and research findings from the recent research and which also suggests that there is a downstream reach and benefit effect from one SC to a non-legal professional in that they often re-use the information in their future work with other clients. 
A SC can sometimes include advice on the workers' professional legal obligations in assisting their clients. It may involve some further agreed collaboration on the issue to discuss or to follow up on the matter. It may also result in the subsequent referral of the client that the non-legal professional is assisting, checking and verifying whether a legal issue is involved or who might be the best referral avenue.

\section{What public legal assistance services in Australia aim to do and gaps in recent research}

Recent research (Balmer, Buck, Patel, Denvir, \& Pleasance, 2010; Balmer et al., 2006; Buck, Balmer \& Pleasance, 2005; Buck et al., 2008; Coumarelos et al., 2012; Schwarz, Allison \& Cunneen, 2013) has shown that clients who are vulnerable and experiencing disadvantage are likely to not only have one legal problem but multiple and cascading problems (often with a legal solution) and multiple complex disadvantages. Around only 13-16 per cent are likely to get help from a lawyer and huge barriers exist for them in getting assistance (Coumarelos et al., 2012).

The key aim of legal assistance services (namely, legal aid commissions, community legal centres, Aboriginal and Torres Strait Islander legal services and family violence prevention services) is to reach clients who need help, specifically targeting people experiencing disadvantage or vulnerability. These are also clients likely to come within the remit of many legal protections around discrimination, debt, poor housing, disability, income security, and access to services.

In Australia, this is in a context of worsening funding shortages despite increasing demand and complexity of needs (Productivity Commission, 2014). This has significant implications as the most at risk are least likely to seek or gain help. Innovative, nontraditional legal practices, including SC, are being undertaken in Australia to overcome the gaps identified in the recent research.

The research has found disadvantaged or vulnerable groups are least likely to seek assistance from a lawyer for their legal problems for a range of reasons, including a lack of money, inability to identify a problem as capable of a legal solution, remoteness, social exclusion, poor education. negative perceptions of lawyers and the legal system (Curran, 2015, 2016c) and other barriers to access (Moorhead, Robinson, \& Matrix Research and Consultancy, 2006; Coumarelos et al., 2012).

\section{Emerging research on addressing barriers to accessing justice}

In Australia, the United States and England it appears that people experiencing disadvantage are likely to go to a trusted health, allied health and social and community service worker or professional with their problems. Problems situated within the meanings of a governing legislative and administrative framework, allow for legal solutions to be negotiated. This article argues that lawyers or paralegals need to go to the places that these people are likely to be, such as hospitals, community health and allied health services, men's sheds, youth, aged care and homeless services, community gatherings, and home visits of non-legal professionals, rather than wait for client's or their professional supports to make an appointment - the traditional model of lawyering (Curran, 2007; Tobin Tyler, 2008; Trubek \& Farnham, 2000; Coumarelos et al., 2012; Productivity Commission, 2014). Critically, lawyers can also work alongside the non-legal workers where these clients are likely to present, building capacity to better 
help clients and identify problems capable of a legal solution in a holistic way, alongside and in partnership with the trusted non-legal workers.

The United States research (Trubek \& Farnham, 2000) and some Canadian research (Roberts \& Currie, 2012) also reveals that many clients are likely to go to a trusted intermediary for help with their problems rather than to a lawyer. The issue is not just that they do not know how to identify a legal issue, which is itself a problem (Productivity Commission, 2014, p. 32, 35, 43), but that they are worried about cost and as discussed above often have negative experiences/perceptions of lawyers and the legal system (Curran, 2016c). These are impediments to people seeking help (Coumarelos et al., 2012; Curran \& Noone, 2007; Curran, 2015).

\section{Literature and research on SCs}

In 2013, when the author started to research SC, a literature reveal revealed that SC has been mentioned and identified, albeit briefly, in other areas of service provision approaches in a non-legal context namely, in cancer care and mental health. An example is 'OnTrac' (Peter MacCallum OnTrac, n.d). This is a state-wide service in SCs to support health professionals by phone or if necessary video link provided by the Peter MacCallum Cancer Institute across Victoria for age-appropriate care to young people living with cancer. There is also a mental health support and diagnosis SC process by the agency, Spectrum (2016). There is a dearth of publically available literature on the impact of SC, however they have been the subject of limited research in non-legal spheres in the United States (Sheridan, Welch, \& Orme, 1996).

The practical experience of the author in providing SCs was that it led to improved reach to vulnerable clients through one on one advice to these non-legal professionals whose clients were otherwise not presenting with their legal issues to legal service. This practical experience is outlined later in this article as it provides direct insights into service provision and may inform policy. It was this practical experience that has led various agencies to approach the author to be involved in advising or conduct the research that is discussed in this article. It was this practical experience which provided the impetus for the author to ascertain if there is an evidence base to support SC effectiveness in reaching those excluding and supporting their professional supporters.

Subsequently, the author's field research and other studies in which she has been involved in an advisory capacity have been undertaken where a component of that research was designed to capture data on use and effectiveness of SC. This work on SC is the focus of this article especially given the gap in empirical data and research on SCs noted above in a legal and non-legal context. The studies consist of different evaluations and quality frameworks in a range of settings in urban, outer urban and rural settings in Australia. These include the author's field research for the Health Justice Partnerships (HJP) of ARC Justice Ltd in Bendigo with the Bendigo Community Health Service; advisory work for the Redfern Community Legal Centre project in the Royal Prince Alfred Hospital's through a partnership 'Aboriginal Medical Legal Service' in inner Sydney; advisory work undertaken for the Legal Services Board and Commissioners, Victoria (LSB) on eight LSB funded HJPs so as to develop common measures additionally with the author facilitating quarterly 'supported evaluation workshops' (involving sixteen partner agencies) around Victoria utilising the author's on-the ground experience of HJP and field research. This article also draws on findings from the research of a specialist Consumer Action Law Centre (CALC)'s where the author has been an advisor since 
June 2012 through a part-time secondment by her university to the agency. As noted earlier the discussion also draws on the author's experience as a lawyer (2001- 2010) in a legal service that was co-located with a health service where the value and benefits of SC became critical to reaching clients, and sparked personal interest in further empirical research on SCs.

In the author's empirical research and practical experience of lawyering, SC emerges as a significant and effective factor in reaching 'hard to reach clients' and in building capacity and, significantly, trust of non-legal professionals to better assist clients with their legal needs and often human rights adherence. The evidence is suggesting that SC is critical to building trust in a lawyer as the pre-condition for many non-lawyers in deciding whether they will refer a client to a lawyer.

\section{SC as 'transferral of trust'}

The author's research reveals with SC a 'transferral of trust' occurs and can be critical if referrals are to occur or reach is to be enabled. This concept of a 'transferred trust' between client and lawyer is because the professional who the client/patient has faith in has had a positive experience of the lawyer. The data from the research suggests that the transferral of trust is due to the trust and confidence the professional has developed in the first instance from their own interaction with the lawyer or agency through SC and, as a consequence, the professional recommends the lawyer to the vulnerable client. Key is the non-legal professional's own development of the trusted relationship with the lawyer if they have received good, accurate, timely and tailored legal advice or information in their SC or in previous other client encounters with the lawyer or service (Curran, Willcox, \& Williams, 2016a). As noted, many clients are not currently seeking legal help from lawyers. This is due to a range of barriers identified in research (Coumarelos et al., 2012) but additionally the author's Bendigo HJP research (this data is discussed later in this article) suggests that many clients may not be 'emotionally ready' to see as lawyer (for example trauma, drug, alcohol, mental health and family violence or negative previous experiences of lawyers and or the adversary system) and rely on the 'trusted' health or allied health professional. This latter group means that SC can be critical. It seems clients are then better prepared to engage with the lawyer based on this 'transferral of trust' from the professional they have dealt with and often have a positive engagement with. When working for clients with complex issues and multiple disadvantages trust can be key to engagement and pathways can be made easier in view of the often overwhelming nature of have multiple and compounding issues to deal with from housing, to income support, access to services, and ill health of family members. In the author's research since 2011 interviews with clients experiencing social exclusion consistently reveals the critical role of trust in terms of their engagement with a professional (Curran, 2012, 2015, 2016a)

As noted, in the academic literature there is little, if any, discussion of the value of SC by a lawyer for non-legal professionals. Yet, there are some signs of emerging awareness. For example, in an evaluation study in Canada SC is noted to be an important in building professional capacity and a willingness to refer vulnerable clients where part of the triage lawyer's role at the children's hospital is 'consultation with clinicians' which and was seen of value in physician engagement, immediacy and training. (Roberts, 2012).

It was also noted as valuable in an Australian study by Noone and Digney (2010): 
'The research identified joint casework, SCs between West Heidelberg Community Legal Service and Banyule Community Health staff and joint community projects by WHCLS and BCH as also important. This collaboration was often connected to referral practice and integral to a holistic approach to assisting a community member with multiple and connected problems and to assisting the community with prevalent problems.' (p. 5)

A recent Australian report further states:

'...the benefits of providing this service include: building capacity amongst health professionals to identify and respond to legal needs and assisting health professionals to understand when a referral to a lawyer may be necessary' (Gyorki, 2014, p. 8).

Attention to the critical role of SCs in not only reaching clients but also building professional capacity to respond to legal issues and extend the reach to otherwise excluded clients is long overdue. The author's research is demonstrating it can be a critical component for improving access to justice and empowering professionals and clients to avail themselves of human rights protections. SC ought to have a symbiotic relationship with professional development training as one can raise awareness of the other and assist in determining matters that might be capable of a legal solution. Training on its own however, may not build the trust to actuate action and confidence to refer a vulnerable client and go beyond the acquisition of the knowledge of a legal avenue.

\section{Research with the Loddon Campaspe Community Legal Centre (LCCLC)}

The value of Professional Development

In May 2015, the author wrote an evaluation report for the Loddon Campaspe Community Legal Centre (LCCLC) on its Family Violence Project, which was funded by the Victorian Legal Services Board. The author developed 'pre' and 'post' Professional Development (PD) Evaluation Forms, which were administered in February 2015, part way into their Project. The forms asked some preliminary questions of General Practitioners (GPs) prior to undertaking the training. The GPs were then asked the same questions in addition to some open questions after the training. The pre-training PD feedback revealed the doctors did not think they needed to know more about family violence mechanisms for their patients. However, on completing the post-PD evaluation form, the doctors acknowledged they had known less than they thought they did and that the training was useful.

Table 1 below provides an example of the responses to one question in the PD Survey which demonstrates the shift in awareness. 
Table 1: All PD Evaluation Survey from Sessions when aggregated (pre and post training) (LCCLC, 2015)

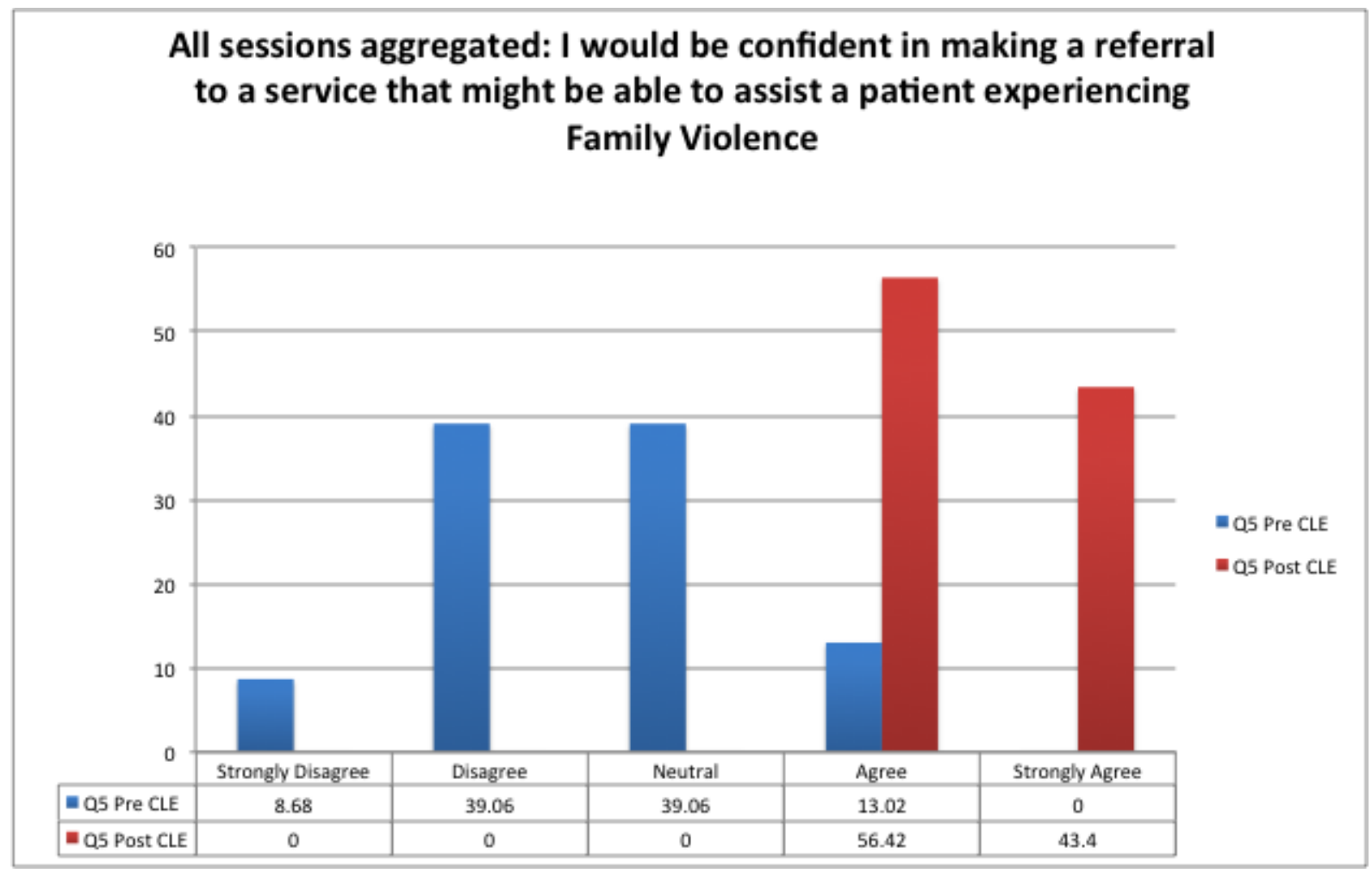

A key challenge is that professionals may not see the value of particular PD around legal options if they think they already have what they need, or have a resistance to lawyers or negative views or experiences of the legal system. Interestingly, once they had attended the family violence training, participants revealed a desire for further targeted interactive training relevant to their practical day-to-day patient consultations. They realised many legal options could assist them in better supporting patients experiencing family violence. Doctors were enticed to attend these sessions, as they were included in their mandatory training. Some indicated that they would have never attended otherwise, but they now realised the training was useful and would not have known this. This breakthrough also shifted when the training was revamped from the previous lecture style pre February 2014 to an adult learning scenario/discussion- based approach tailored to patient experience.

A key challenge for the legal sector is how to strategically make PD offerings attractive, accessible, in plain English, practically useful, less mysterious and meaningful, and to integrate such training within existing training frameworks of other professionals but not increase already burdensome work training requirements of non-legal professionals. The author suggests training can be linked to SCs and the two, when combined, can reach clients and patients who might otherwise be excluded facilitating an informed choice and availing themselves of the rule of law in terms of being able to be heard and have their rights enforced or adhered to.

Many non-legal professionals have been found to not be aware of the range of legal problems with which lawyers can assist (Noone \& Digney, 2010). In the author's long 
experience in the provision of professional training, some lawyers, like some doctors, assume they have all the necessary knowledge. Sensitivity is therefore needed keeping an open mind and listening to others about what they think, need and how what is being offered can help them in their work. One approach could be the old 'appealing to selfego' (Neville \& Dalmau, 2008) that change managers claim is critical in order to get a shift in mind-set - the 'what's in it for me' consideration. Approaches like 'this will better help you assist your clients or patients', imply that professionals are not already assisting clients effectively. The legal sector needs to 'join the dots' clearly explaining what a legal problem looks like, and how, if unresolved, it can lead to poor health outcomes (stress and anxiety), how it can manifest and that it might be resolved in a way that can be negotiated rather than requiring an adversarial setting. SCs and the professional development than runs alongside, can effectively demonstrate why legal help will support them in helping their clients/patients. This approach relies on trust, taking time to listen and tailoring PD to the particular and practical needs of the professionals' clients/patients. Feedback captured in the author's research reveals if this does not occur non-legal professionals will just not engage.

\section{Working together - barriers to collaboration}

Part of the Family Violence Project of the LCCLC, involved developing a new survey instrument (the Collaborative Health Survey Tool) to measure experiences and views on effective collaboration between health and legal service providers in family violence matters. The survey was conducted from 1 February until 31 March 2015. The data was aggregated by LCCLC ${ }^{2}$ and the author examined the results for an evaluation. One hundred and eighteen professionals participated in the Collaborative Survey, with 60 per cent from the health sector and 40 per cent from the legal sector. What is of particular relevance to this article, in terms of barriers to working with legal professionals, were some of the views expressed by lawyers about non-lawyers and vice versa in this study.

Many participants had previously experienced the legal profession in an adversarial setting either as a witness under cross-examination or had poor experiences of lawyers in their personal lives. The results revealed that community lawyers often accustomed to working in community settings were easier to work with than lawyers in some private practices which operate as businesses where 'time is money.' Non-legal professionals perceived they received short shrift or a focus on court outcomes rather than client outcomes. This grated with the professional concerns of health, allied health and social service agencies, and led to miscommunication and abrupt treatment which colours nonlegal professionals' views on the legal profession.

By way of example some of the critical feedback on lawyers from non-legal professions included key descriptions such as abrupt, dismissive, arrogant, rude, disrespectful, condescending, false hope, negative, jargon, unresponsive and judgmental.

Some comments on the lawyers included:

NOT listening, not making time for clients concerns to be heard and addressed in a professional matter. I know lawyers are very busy on the

\footnotetext{
${ }^{2}$ This view tended to not be stated in relation to community lawyers but there may have been bias as the tool was being administered by a CLC.
} 
day of court but clients are people with feelings and often they really are not heard by the legal system.

Impatient manner when client finds options difficult to process quickly. Hanging up on a vulnerable client where there was a conflict instead of providing a referral. Sending a legal letter with complex information with no attempt to ensure that the client could understand it.

Disrespectful of my skills and knowledge just because I do not have a law degree.

Similarly, lawyer comments about non-legal professionals included:

... they undermined the advice or messaging of the legal representative by dismissing or incorrectly questioning it.

Health providers need to be willing to provide detailed reports of the client's circumstances, beyond what is included in a medical certificate.

On a more positive note, the non-legal professionals also commented:

Both parties being dedicated to the wellbeing of the client, respectful of the different approaches each may have (best interests of the client versus client instructions).

Acknowledging that different professionals all have skills and knowledge to share.

And the lawyers:

An open dialogue with the heath service or social services professional means that the client is better supported as different services are on the same page. It is beneficial to have an extra communication link between a worker and a client, as the worker generally has more contact with the client and often sees the client face to face, making it easier to explain issues that may arise - particularly when there are mental health and homelessness issues.

The results and use more widely of the Collaborative Health Survey Tool (which was only limited to the pilot service on family violence in the Greater Bendigo regions) could assist health and legal services in informing practices around barriers, facilitators and impediments. It will be a useful tool in addressing emerging training gaps and professional misunderstandings, which act as barriers to effective client service through collaboration. The survey results reveal that further work needs to be done to build understandings around different cultures and modes of operation between the professions.

It would be useful for this tool to be administered more widely to gauge the extent of the barriers and any improvements. The survey data in the small LCCLC study reveals the reasons for some reluctance in professionals working together that may have been invisible. 
The author stressed in the evaluation report that 'workarounds' (Gyorki, 2014) that respect the various differences in roles and improvements to communication styles and mutual respect and transparency can increase holistic responses to those most in need of help on a range of issues. More respectful dialogue and clearer explanations of legal and ethical complications will help in working towards good practice (Tobin Tyler, 2008) that does not compromise confidentiality or conflict of interest rules, and seems to be a sensible step.

The survey responses revealed that some lawyers can tend to see themselves as the font of all wisdom, and are perceived as arrogant and unhelpful. This perhaps reflects that often lawyers tend to be task-oriented and consider things with a technical lens and do not fully appreciate other contexts in which other professionals also operate.

It is so important for clients to gain full help in a range of legal and non-legal issues to be able to access their legal rights. Where only 13-16 per cent of vulnerable clients have been gaining legal help, such professional barriers need to be overcome (Coumarelos et al., 2012). Understandably, consciously or unconsciously, before a non-legal professional (with their own professional obligations to their client) will be prepared to refer a vulnerable client or patient to a lawyer, it is natural for them to only do so where the lawyer is seen as an effective communicator, personable and trustworthy; someone, who will not just be concerned with the client's technical legal issues without heed to the client's context and personal circumstances such as ill health or being overwhelmed. Where the non-legal professional trusts the lawyer and gains a sense that they will work effectively with a client in a way that is in line with the therapeutic framework and which will not re-traumatise, then they will be more likely to have a conversation with a client who may, in turn be more willing to see a lawyer. In other words, what this article terms, a 'transferral of trust'. If the non-legal professional trusts the lawyer and indicates this to the client, then the client who trusts the existing relationship with the non-legal professional is likely to be more willing to see the lawyer.

The author has two decades of work with clients who, as refugees, have experienced torture and trauma; people who have been victims of institutional sexual abuse; people with intellectual disabilities; people with drug addictions and homeless clients. These are examples of people who have good reason to distrust authority and have often seen the legal system in adversarial contexts. Lawyers can no longer assume all people with legal problems will know how to identify an issue as legal, make an appointment with a legal adviser, or easily overcome experiences, disempowerment or fear of reprisals. This is particularly the case for the groups identified earlier in this paragraph who experience social exclusion. The empirical research is clear that these clients are not seeking or accessing legal help when they need it (Coumarelos et al., 2012).

\section{Barriers in working with lawyers}

A significant challenge for lawyers seeking to work with other disciplines is long running negative stereotypes of lawyers held by other professionals, views which may be based on personal experience.

The problem presented is an atmosphere of distrust, fear and antagonism not all of which is unfounded. It is the result of a lack of communication; failure of understanding of basic professional objectives, methods and philosophy of the co-professional; and above all, the mystique built up by 
ever increasing malpractice insurance rates. (Norton, 1971 as cited in Tobin Tyler, 2008, p. 2)

Working with lawyers in a multi-disciplinary practice or through outreach at non-legal services presents barriers that do not exist for other professions. Many non-legal professionals may have had prior dealings with lawyers as witnesses, under crossexamination, in adversarial settings or had poor experiences of the law and lawyers in the past (Tobin Tyler, 2008, p. 2). As well, most people's exposure to lawyers is through television where they are depicted as aggressive or 'guns for hire' (Griffiths-Baker, 2015). Shows such as 'Boston Legal' and 'Suits' are widely known but set in the United States with a vastly different ethical codes to Australian lawyers. Unethical depiction of lawyers in Australia in shows such as 'Crownies' and 'Rake' also inform local perceptions of lawyers. If this is a perception be it false or true, it is hardly the sort of lawyer a professional will want to expose a very vulnerable client to.

By way of example, medical and allied health professionals can often be at the front line of family violence with patients presenting with injuries as a result of violence or disclosing risks to their safety or of the safety of children. If a pregnant woman presents to a hospital with injuries or discloses fear to an allied health professional, for example, in an hour-long physio-therapy session at a community health centre, the ability to gain quick legal advice by the trusted health professional on the spot for the woman may be critical. If the health professional's only experience of a lawyer was in an adversarial medical negligence case they may be reticent to refer to a lawyer as they fear it might re-traumatise a patient. If a community lawyer with certain attributes that break down such barriers is able to work with a multi -disciplinary team, highlight the role of lawyer as problem solver rather than litigator and build trust, the likelihood of a referral is enhanced.

\section{The value of Secondary Consultation - personal experience}

The traditional focus in Australia and abroad in legal service delivery, be it by private lawyers or through salaried legal assistance, has often been limited to purely legal advice, information and representation with the contact point being the appointment made by a client. This model assumes that clients know enough about the law and their rights or have the money or access to lawyers to make an appointment. The author worked in a community legal service from 2001 until 2010, first as an academic supervising a clinical legal education program (where student lawyers delivered legal services under the author's supervision) and later as a Director of the service. The practice was in an urban legal service on a public housing estate and co-located with a health service (pre-dating the recent Australian research and the rise of an HJP movement from 2012). Feedback from health service professionals noted that having a lawyer available for SC provided critical assistance for them in assisting clients/patients. This finding was partly documented in Noone and Digney's research (2010). More detail on the concrete operations of this practical experience of the author (given it occurred for ten years) is detailed in this article so as to inform sustainable practice and the nuances so as to compliment the research examined and to inform readers who might be considering SC in their service or policy settings.

As the Clinical Supervising Solicitor, the author would get daily requests from non-legal professionals about legal matters. These included checking a court letter for a client, helping them prepare to be a witness, advise what to expect at court or what were 
relevant considerations for a court report the professional is required to submit. Many professionals would ask about their legal and ethical obligations. Others would ask for guidance on whether a client's problem was a legal issue. For example, a letter from social security demanding the patient provide information that seemed unreasonable to the professional. Through a brief SC with the lawyer the departmental request was identified as an unlawful request. Once the non-legal professional knew a problem might be a legal matter, the author could help the client either through the worker (as some clients were not emotionally ready to see a lawyer) or could see the client. Rarely were the non-legal professionals aware of the vast aspects of daily life that are governed, permitted or circumscribed by laws and regulations.

Regimes around housing standards, obligations of public authorities to abide by human rights standards (especially in the ACT and Victoria) participation and treatment in employment, by health services, safety and family connections, planning, health care, environmental impacts, social security, social, cultural and economic rights and consumer protection are all areas where legal frameworks exist and do not require navigating court or non-adversarial settings. There are remedies and complaints mechanisms or rights to rectification and decision-making that take into account human rights standards and equal opportunity and non-discrimination practice. Survey responses in Noone and Digney's research (2010) revealed that health professionals perceive legal issues as limited to criminal and family law and often do not turn their minds to the vast areas where clients' problems may have legal avenues or solutions (Coumarelos et al., 2012; Noone \& Digney, 2010). Some members of the public and their professionals are poorly informed or not confident in questioning powerful authorities. Lawyers can meet this gap through SC on legal rights and provision of advice how to navigate and negotiate for legal adherence or facilitate negotiated outcomes.

Alongside SCs the author would run sequenced sessions for the professional staff to address common concerns and upskilling needed for day-to-day work. In this process, the author would also attend the non-legal professional development sessions and also learn about issues affecting clients, for example, the impact of side effects from clients' mental health medication on the non-legal professionals. Capacity of lawyer and nonlegal professional to better support clients was built. Sometimes at these sessions a legal point in need of clarification might arise and the author would be asked to respond or look into it further and follow-up. For example, on one occasion the Chief Executive Officer asked about the obligations of the health service under the Victorian Charter of Human Rights and Responsibilities as the health service was a 'public authority' with certain Charter obligations towards its clients. This 'opportunistic' ability to address legal issues as and when they emerged was also critical in building staff and management capacity. Availability was key to building trust of other professionals, breaking down negative stereotypes of the adversarial nature of lawyers and correcting misunderstandings of the laws and legal processes.

\section{Building relationships between practitioners and identifying measures}

After a nine-month break working for a humanitarian organisation, the author returned to the same legal service as Director. In the interval there had been an observable deterioration in the relationship between the legal service and the health centre's workers which included doctors, nurses, social workers, counsellors, occupational therapists, drug and alcohol workers, neighbourhood renewal, financial counsellors, 
gamblers help, psychologists. A strategy to win back the trust of the health service workers and their team leaders was needed.

The next segment of this article will highlight the critical role and value of time spent on relationships between professionals by identifying the measures that were implemented to enhance relationships so as to reach clients and encourage referrals. The time needed to build, consolidate and sustain relationships, is immense, but in the author's experience gives significant and long term returns for clients. The data for the service revealed that the legal service was not engaging significant vulnerable groups including victims of family violence, members of the local Indigenous community, asylum seekers and refugees, youth, people with mental illness, people experiencing trauma and victims of institutional abuse and homeless people. Clients tended to be repeat clients using the criminal law service even though there was a legal aid office in the area.

The next section of this article will unpack how the SC process can work. In initial weeks and months in the role of Director, the author visited the different teams (doctors, maternal and child health nurses, counsellors, psychologists and social workers); attended health service staff meetings and asked how the legal service could assist them better. They reported on promises made and not kept, a lack of communication, poor client experiences of the legal service and concerns lawyers no longer attended joint training or professional development sessions as they were 'too busy'. They reported that lawyers could be aloof and 'condescending', and made the law seem technical and beyond the capability of workers. They noted that lawyers used to be available to help when a worker stumbled upon a tricky legal issue, but that this support had shifted. They noted once trust and the relationship were lost it was hard for it to be regained.

As Director, the first step was to clearly clarify and articulate what the service was able and not able to do and why. This was to ensure that professionals knew the scope and extent of the service's capacity given limited funding of legal centres and explain limitations and manage expectations. Next a service charter was developed outlining not just the clients' obligations but also the legal services' obligations to clients and other services. The service charter also contained the avenues for complaint against the legal service. This charter was placed visibly around the building. The author consulted with the health service staff on their views and incorporated their suggestions.

Pertinent for SC, was the adoption of an 'open door policy'. The Director's Office was in an easily accessible corridor and professional after professional would call in, close the door for a few minutes to seek legal advice (i.e.SC). Examples include: multiple short advices to the worker to confirm a matter was a legal and immediate referrals, i.e. worker bringing homeless clients and family violence victims straight to the interview room as they were at risk of giving up, the organisation of a roundtable to negotiate for a child in care to be reunited with their foster family which was previously prevented by a government departmental mistake, a conference with a client's school representatives, decision makers and family members to enable supports for family and for the client to continue their schooling rather than be excluded. All of these concern human rights adherence. Often the advice would be short and to the point. Specific clients were not mentioned to avert conflicts with other confidential client work. Brief notes were kept on the advice provided and kept in a SC file. Professionals' comments included: 'I am so glad I spoke to you about what to expect at court today and I would not have gotten any sleep last night without it'; 'the client said my letter of support was referred to as of great 
assistance in sentencing'; 'the child has irregular bowels, since you got rid of the mobile phone debt his anxiety has completely gone'. The author realised that SC, even of short duration, could reap many rewards downstream including the confidence of the nonlegal professionals, their peace of mind and clarity about complex legal processes and how to navigate them. There were also some opportunities for joint systemic policy work on public housing by the legal service in partnership with the health service using the human rights framework as the basis for the submission. The legal service was reaching clients who would otherwise never seek legal help through engaging with health and allied health professionals. It was clearly extending the reach of the legal services beyond the clients it used to see.

The author started routinely counting the number of SCs occurring each week, briefly recording the feedback and the nature of queries to inform professional development and compile a written record. As new staff were hired they were encouraged to also record. Conflicts of interest (namely, information about a client that could compromise another client the service is acting for) were carefully managed and simply explained to the professionals so they all became aware and would flag what they needed to avoid saying or gain relevant client consents or referrals.

After keeping SC data over a twelve-month period these were reported the health service's board. The data revealed five SCs per day five times a week, averaging out at 1200 per annum. Prior to this no data on SC had been kept and although SCs were being undertaken, their value and the time taken had not been considered by management or by the legal aid and governments that funded the service. The flow-on benefits for staff and clients from the SCs were becoming evident as a result of being documented. The health service staff were happy and had more confidence when referring a vulnerable client that the legal service would deliver. This sentiment was reflected in concurrent professional development on topics the health service staff identified in conversations and from sequenced training on areas they noted they would like to know more about, for example, using the human rights charter in their day-to-day work.

Within six months the legal service's casework started to reflect a broader range of people with increasing numbers of Indigenous, mentally ill, and newly arrived refugees and migrants referred by the doctors, counsellors, maternal and child health nurses and other professionals at the co-located health service.

Previously staff had not realised that issues related to debt, discrimination, poor housing, evictions, and family violence were legal in nature. Training on problem identification with the different teams using scenarios and questions on their own practice experience opened their eyes to the scope and power of the law. Many staff felt positioned to mount arguments to decision-makers after training.

In terms of fines I would high tail it up here and seeing the legal service...a good example of me utilising the legal service recently... is a woman who came from a refugee camp....(after advice from the lawyer)... I wrote a letter to the hospital saying that this person is an asylum seeker, does not have Medicare at the moment but that we have an obligation (under the Charter) to provide her with free services......several years ago the government put out a directive to all hospitals, medical services, including dental, that asylum seekers in regard to Medicare had to have free services..... I wrote to the 
senior social worker who sent an email to the entire hospital saying that...and I also produced cards saying that "I am an asylum seeker, I am entitled to free services at [service name].....every organisation was given that letter, and I have copies so I can bring them out and quote them..........the legal service supported me in that knowledge and said if you have any problems get back to me. (Noone \& Digney, 2010, p. 122)

SCs need to be counted alongside the other data required by funding agencies. From $2008-2010$, during the author's time as Director of the legal service, it was apparent that SC were of value and critical to relationships of trust, building wise referrals and helping clients through other professionals that the legal service would otherwise not reach. The remainder of this article will canvas some preliminary findings from the author's research.

\section{Gathering empirical data - Research with the Consumer Action Law Centre (CALC)}

As noted, there is little literature or data on the value of legal and social work and public health SCs (using various search terms including 'worker support', 'secondary advice') there is some (but also limited) across the medical, social service or mental health spheres). However, one early reference study of literature notes:

In general, consultation was found to produce at least some positive results in $76 \%$ of the studies reviewed. Thirty-three percent of the studies reported some neutral results (i.e., no changes, changes on some measures but not others, or no difference compared to control groups), and $4 \%$ of the studies reported at least some negative results. When considering all of the outcomes reported across studies (i.e., 60 outcomes reported across the 46 studies), $67 \%$ were positive, $28 \%$ were neutral, and $5 \%$ were negative. Following this general level of analysis, a review of use and outcome by consultation model was conducted. (Sheridan et al.,1996, p. 344)

Sheridan et al. (1996) note more research into SC is needed.

As a part of the author's university role she is seconded on a part-time basis to the Consumer Action (CALC) in Victoria. Given her practical experience of SC she was asked to advise on a project evaluation being conducted by CALC. This work in relation to $\mathrm{SC}$ is in an advisory capacity only and CALC undertook the evaluation in-house. CALC is a state-wide specialist consumer law centre which runs a phone advice line, conducts public interest test cases and engages in policy reform and legal education. The clients targeted are those on low incomes and vulnerable groups. CALC (formerly the Consumer Credit Legal Service (CCLS) has had a worker advice and support line since 1984. CCLS started in its first few years with no funds for lawyers. Each Wednesday night clients would come in and usually be interviewed by a lawyer and financial counsellor (FC). The volunteer FCs would talk to the lawyers about cases, so the idea of FCs getting advice from CCLS came as a natural part of this co-location. Consumer Affairs Victoria (the regulator of consumer laws in Victoria) saw the value of 'worked support' (i.e. SCs) and agreed to fund them. Since late 2014, the author has been developing a quality and evaluation framework and collecting data on SCs from the 'worker line', including capturing the extent and reach of the SCs to workers and hard to 
reach clients. Data has previously been collected partly through the 'clunky' Community Legal Service Information System (CLSIS) (Curran, 2013) by CALC, which has been deidentified and aggregated for the current research. From January 2012- December 2014 CALC undertook 1755 SCs with an additional 639 becoming extended advices. This means CALC has a strong foundation to inform future SC, as summarised in Table 2.

Table 2: CALC Worker Advices Breakdown Aggregated Data

\begin{tabular}{|l|l|l|l|l|l|l|l|}
\hline $\begin{array}{l}\text { Type of workers accessing the } \\
\text { service }\end{array}$ & $\begin{array}{l}\text { Jan- } \\
\text { July } \\
\mathbf{2 0 1 2}\end{array}$ & $\begin{array}{l}\text { July- } \\
\text { Dec } \\
\mathbf{2 0 1 2}\end{array}$ & $\begin{array}{l}\text { Jan- } \\
\text { June } \\
\mathbf{2 0 1 3}\end{array}$ & $\begin{array}{l}\text { July- } \\
\text { Dec } \\
\mathbf{2 0 1 3}\end{array}$ & $\begin{array}{l}\text { Jan- } \\
\text { June } \\
\mathbf{2 0 1 4}\end{array}$ & $\begin{array}{l}\text { July-Dec } \\
\mathbf{2 0 1 4} \\
\text { (new format) }\end{array}$ \\
\hline Financial Counsellors & 250 & 249 & 234 & 223 & 217 & $54.4 \%$ \\
\hline Other Not For Profit workers & 33 & 41 & 52 & 49 & 33 & $13.3 \%$ \\
\hline $\begin{array}{l}\text { Level of service provided / \# } \\
\text { workers helped }\end{array}$ & 297 & 224 & 382 & 347 & 259 & 246 \\
\hline Advice & 167 & 120 & 93 & 84 & 100 & \\
\hline Complex Advice Cases & & & & & & 61 \\
\hline Information & & & & & & 75 \\
\hline Extended Advice & & & & & & 13 \\
\hline Case file & & & & & & 26 \\
\hline No Action & 267 & 289 & 372 & 357 & 257 & \\
\hline Frequency of access & 95 & 91 & 107 & 85 & 85 & \\
\hline Used service once & & 33 & 83 & 46 & 41 & 36 \\
\hline Used service 2-5 times & & & & & & \\
\hline Used service over 5 times & & & & & \\
\hline Metro & & & & & \\
\hline Rural & & & & & \\
\hline
\end{tabular}

The existing data does not disclose the impact or effectiveness of the intervention. The author was asked by CALC to advise on how they might track and measure this into the future from 2016 to develop tools to measure the reach and the flow-on impact of SCs for workers and clients. This advice led to further evaluation of the worker advice line in early 2016 using a mixed methodology of an on-line survey and focus group which will be replicated each year. A report on the findings was released in July 2016 (Curran et al., 2016a). The main recipients of LSCs (76\%) were financial counsellors, followed by other non-legal workers (14\%) and community lawyers (10\%). This work in 2016 included a Focus Group of eight financial counsellors facilitated by the author. Some comments include: 
Essential (SC) where clients approach you and you don't know what to do. There are a number of things going on and so getting legal advice in different ways along the way as you assist clients is clearly helpful.

I always get good advice from CALC (all participants nodded) and I always call Where things are technical you can get advice and sometimes act and other times the lawyer can step in. It's immediate and useful.

I had an intellectually disabled client. I was reluctant to break the relationship and so I got guidance from the lawyer, used the fact sheets on the web site and then started to sort the bank out. I could then check in with the lawyer from time to time to get the support I needed. When the bank said that or this I could check in with the lawyer to see if the bank was right and then go back and challenge them.

It can be great when you talk to the lawyers they sometimes give you the specific legislation and so when you got back to the car dealer etc. you can sound more authoritative.

Yep doesn't hurt if you can say taken legal advice then they back off.

The general perception of lawyers is bad and most of our vulnerable clients are scared of lawyers and so having a support person like an FC or social worker who can liaise with a lawyer through SC can break this and if we need to refer if we know the lawyer or trust the agency the client might be more prepared to see that lawyer but there has to be follow through by the lawyer otherwise it affects our own relationship with the client.

In this 2016 work the on-line Survey was conducted and promoted by CALC through the peak body in Victoria for financial counselling (FC) and there were fifty participants. In the on-line Survey positive responses (93.6\%) were received in relation to propositions that workers understand and value the advice CALC lawyers provide through SC. CALC has recently expanded its SCs to a number of non-financial counselling services in view of the findings of the Australia-wide Law Survey (Coumarelos et al., 2012) mentioned above and as a result of the current author's findings elsewhere in HJP research which will be discussed in the next section. This wider group of professionals to whom CALC has commenced rolling out SCs includes Aboriginal services, youth workers, counsellors and social workers. CALC has also now adopted the term 'SC in their materials.

Given CALC's outreach experience, it already has many processes in place. In February-April 2015 it conducted feedback roundtables with FCs about SC and identifies elements critical to SC effectiveness. CALC subsequently developed a Service Charter in consultation with the author, the feedback on which reveals the value of SCs and what factors make them effective.

In summary the feedback roundtables conducted by CALC revealed, FCs are more likely to call the CALC 'Worker Support' line for SC when:

- dealing with a legal situation that is new to them

- dealing with a topic they are uncertain of

- dealing with a new product or service

- dealing with contract matters, especially 'dodgy' contracts

- the legal issues become technical rather than straightforward 
- they need to update their knowledge on an issue, or check that their knowledge is still current.

Some FCs like written confirmation of advice. They can then copy and paste the advice into file-notes for the benefit of co-workers. Some lawyers are already offering to follow up by email.

FCs indicated that effective SCs included:

- concrete, practical and specific advice as this is more helpful than vague or general information or legalese

- a next step or step-by-step advice or assistance with a client, a strategy, or options to help workers

- to be made to feel as though they are working with lawyers in a team, rather than being dealt with at arm's length

- for lawyers to share their enthusiasm and passion for helping their clients, to help maintain motivation.

Early indications are that a short advice through a SC can reach clients who would otherwise not seek legal help. A 'trusted intermediary' encourages and contextualises the issue if legal in nature and creates pathways for a client to gain advice or uses the information to support their client directly. This is especially useful given the lack of legal service personnel to match the need and extends the reach of the service.

\section{Other Project Involvement Relevant to Measuring Impact of Secondary Consultations}

It is important in the context of this article to situate the discussion of SC within the broader context of the research. Because the Bendigo HJP evaluation and advisory HJP projects (funded by the LSB) have embedded evaluation from service start-up, this enables some interesting data to be collated on the impact of SCs in the longer term and preliminary findings have been shared along the way.

As well as the empirical research, the author has been commissioned by the LSB as an advisor from September 2014 to facilitate quarterly workshops where common benchmarks for evaluating the effectiveness and impact of HJPs and effect on the social determinants of health (through the collaborative process with service partners, legal and non-legal). The emerging research from the eight HJPs funded by the LSB (with at least sixteen partners - health, social welfare, youth and multicultural services) has also highlighted the value of SC and seen its measurement incorporated into future data collection for these services. This is detailed in further detail in a report (Curran, Wong, \& Ball, 2016b).

\section{Field Research: How does SC benefit clients? - Bendigo Health Justice Partnership}

\section{Context of this research}

Since mid-2014 the author has deliberately decided to test the value of SC in the research evaluation of HJPs (informed by the utility of SC from practical experience as a lawyer). This has been achieved by developing an enquiry tool to directly ask the non- 
legal professionals whether SCs were conducted and their perceived value and impact for clients. An empirical basis is now emerging for concluding that SCs are an effective way of enhancing people's human rights and reaching those who would otherwise not gain help. This research which had university and health service ethics approval concluded in June 2016 reveals that not only does SC assist clients but also builds the confidence and capacity of non-legal professionals to better respond to client/patient needs and to assist in effective and timely referrals.

In the Bendigo HJP research, the author interviewed ten clients (the numbers were smalls as the research was conducted in week long snapshots and as the project had one lawyer and each client had multiple legal issues (91\%). She also conducted eighteen in-depth ( 2.5 hour long) interviews with health and allied health professionals.

\section{Action research methodology}

ARC Justice Bendigo Ltd commissioned the author to conduct a research evaluation in July 2014. The Bendigo HJP (ARC Justice Ltd and the Bendigo Community Health Service (BCHS) is an embedded collaborative action research and reflective practice model of evaluation. Participants in the research include community members, clients, professionals, administration support, managers and external organisations also assisting in the project's design. This approach was deliberate to ensure the process was informed by the reality of the service and those using the service. This process (also informed by worldwide research in the human services, public health and humanitarian spheres) identified a number of proxies, which, if they were present, were indicative of a positive impact on social and health determinants (Better Health Channel, 2011; CSDH, 2008.

Poverty and low living standards are powerful determinants of ill-health and health inequity. They have significant consequences for ECD and lifelong trajectories, among others, through crowded living conditions, lack of basic amenities, unsafe neighbourhoods, parental stress, and lack of food security. Child poverty and transmission of poverty from generation to generation are major obstacles to improving population health and reducing health inequity. (CSDH, 2007, p. 84)

Elements leading to a positive outcome for clients and likely to increase the capacity of professionals to gain legal support and information were built into measurement. Enabling a 'transferral of trust' from non-legal professional to client whilst also improving both client and professional engagement was determined to be critical. The Bendigo research saw the development of some proxies (indicators) to measure the social determinants of health impact which have been adopted by the LSB funded services in their evaluations. If the proxies are present then they are suggestive of positive impact or outcomes on the social determinants of health (CSDH, 2008; WHO, 2008 Green, Betancourt, \& Carillo, 2008; Healthy People, 2020, 2014). The proxies are as follows:

- Engagement - client/patient/professional and staff

- Collaboration - client/patient/professional and staff

- Capacity - client/patient/professional and staff

- Empowerment - client/patient/professional and staff -includes giving voice for client/patient/professional and staff and improved advocacy for client/patient/professional towards systemic change 
These proxies do not stand-alone and are inter-related and intersect to increase the likelihood of people exercising their human rights.

\section{Findings from Bendigo HJP specific to SCs}

A range of themes have emerged from this broader research, but this article will focus on those most pertinent to SC. The specific target group for the HJP relates very specifically to include social workers, general counsellors working with children with disabilities and their families to strengthen their capacity and resilience, outside of the formal child protection system; the Child Health Invest: including child counsellors; Alcohol and Drug treatment) workers, paediatricians, social workers and nurses and a specialist Autism Assessment Program and allied health professionals with the Early Years team which supports families of children with a disability aged less than 6 years. These families and children, the author's research is confirming, are members of the community often with little voice and who but for the community health service would be even socially excluded.

The Bendigo HJP Evaluation was being conducted through snapshots over time so as to reduce the burden of data collection on staff (whose main role is to deliver direct services to clients and who have significant caseloads) and to enable a longitudinal study. Numerous tools were used and quantitative and qualitative data was collected and analysed after snapshots and aggregated over the life of the project. The first twoweek trial snapshot of the tools occurred in the weeks of 20-25 April 2015 (Snapshot One also piloted the methodology). It was repeated from 6-10 November 2015 (Snapshot Two) and in 2-6 May 2016 (Snapshot Three).

The critical tools extracting relevant data on SCs are as follows:

The instruments and number of participants over the life of the project were as follows:

- Community Focus Group (26)

- Client Interviews x 10

- Longitudinal client case studies (7)

- In-depth Interviews with health/allied health professionals' x 18 (Approximately six health and allied health professionals were re-interviewed in each snapshot to enable short, medium and long term comparisons through the project snapshots). There was an increase of health and allied health professionals by the Final Snapshot suggesting increased engagement over the life of the project of the health/allied health professionals in the HJP.

- In-depth Interview with lawyers' x 6. (The lawyer staff was consistent and they were re-interviewed in snapshots to enable short, medium and long term comparisons through the project snapshots.)

- Interview with Reception x 6 (The reception staff was consistent and they were re-interviewed in each snapshot to enable short, medium and long term comparisons through the project snapshots.)

- Interview with Relationship-holders' x 18 (includes 10 Managers \& 8 external agencies). Three of the managers were reinterviewed in each Snapshot to enable short, medium and long term comparisons through the project snapshots. Similarly, two external agencies were re-interviewed in each Snapshot). For the Final Snapshot a decision was made by the author in discussion with ARC Justice, that, given the data from externals was consistent from Snapshot One 
and Two (and unlikely to change given they had reiterated similar point in each snapshots) and due to the increased number of in-depth interviews with health/allied health professional staff resource and time wise and in terms of data significance it was best to interview less external agencies in Snapshot Three.

- On-line Survey of BCHS staff (53) across all Bendigo Community Health sites (not just the Kangaroo Flat where the Bendigo Health Justice Partnership was conducted.

- Case Studies from the qualitative data (23)

- Aggregated service data provided to the author by ARC Justice from 7 January 30 June 2016.

The Research Findings reveal mutual benefits for capacity of staff and for client outcomes:

- A service which is a HJP needs to be 'opportunistic' in taking advantage of the client's health appointments to provide legal assistance - due to complexities of the lives and confusion, lack of confidence and being overwhelmed etc. SC are pivotal in this.

- The capacity of professionals both lawyers and non-lawyers as well as client service staff is key/critical to being able to support clients in a timely way and when in crisis or ready for help.

- SC are often short in duration which for time poor professionals with significant caseloads can be key.

- Health/allied health professionals reported using SC to test the lawyer before making a referral and as critical to building trust. They used it to check in and verify facts, for their own personal peace of mind and to reduce their stress.

- HJPs if they are not already doing so ought to routinely count and value the time spent by the lawyer/s on SC as part of its data collection given SC are so critical to the HJP's effectiveness and engagement with both clients and legal professionals.

The data revealed of the he health/allied health professional participants $81.9 \%$ strongly agree and $18.2 \%$ agree there is 'huge value' to them in LSC (100\% positive view on its value)

This discussion now seeks to highlight the value of qualitative data, as evidenced through some of the responses elicited to date in the BCHS snapshots.

\section{Professional Journals}

Had a client who was concerned about her rights as a grandmother in a custody battle with her daughter's e -, Children's Court in Melbourne, child protection requests, access to the children, living arrangements and seemed generally confused about process. I was able to introduce the client to [Lawyer] with great effect. [Lawyer] was able to guide client in process and give information about requirements and inform of potential outcome, then client options once outcome determined. Invaluable as I could not have provided this... I still see such huge value in having a lawyer on site for the 
spontaneous meetings that would not be possible without having [Lawyer] physically here. Also by just having access to [Lawyer] allows me to do my job more holistically through secondary consult with [Lawyer] and really just more confidence in opening legal issues as I can then get advice for the client which may lead to reduced stress for this client, ultimately leading to a better health outcome. (Nurse)

Having a solicitor accessible made it easier for me as a counsellor not to be drawn into giving advice outside of my area of expertise. As [Lawyer] is available and easy to access the client readily accepted this re-direction and did not press me to give my opinion of contact arrangements (Social Worker)

...It is efficient and time effective to have colleagues from other disciplines and lawyer co-located as I can walk past [Lawyer's] office and know when [Lawyer] is free to speak to me or we can schedule a suitable time. This saves time and is more efficient and effective for us both. (Social Worker)

\section{In-depth interviews}

The in-depth interview participants stated that Legal Secondary Consultations (LSC) 'are pivotal', 'it would not work if we did not have LSCs'. A significant majority of research participants noted that LSC enables quick, efficient and targeted building of knowledge which can 'save time' in the long run. LSC need to be done well as they are so critical to engaging and reaching vulnerable and disadvantaged clients.

\section{Sample questions}

Question 5: SCs are when the lawyer offers you legal advice or information or advice on the legal processes (what happens at court, giving evidence and writing reports), ethics or your professional obligations or guides you through tricky situations. Have you received SC assistance from the lawyer?

Yes: 91 per cent; No: 9 per cent

5 a) If so, describe the sort of situation without giving away any information that will identify a client.

I use the advice I received all the time now. I will talk to [Lawyer] when a client has a legal issue and they / I don't know what to do about it. (Counsellor)

5 b) What has been the value to you of SCs if you have received any?

Personally increased my confidence and has supported my advice giving to clients. Accurate advice helps me. (Counsellor)

I now know that sometimes when the Department says it's a 'no' to my client that they may be wrong and I feel better able to question it as the legal advice shows me a 'no' is often a 'maybe'. (Nurse) 
Added knowledge imparted by [Lawyer] and the 'lawyer lens'. Helps to understand the full ambit of the clients' issues. [Lawyer] corrects professional staff assumptions. Builds upon my practice [making it] 'more wholesome practice'. Knowledge increases, positive outcome from lawyer...my ongoing interaction with clients improves. (Social Worker)

The responses to $5 \mathrm{c}$ ) below highlight how without SCs people least likely to gain legal help who are likely to have human rights concerns can be reached (such as children, young people, Indigenous people, people with disabilities)

$5 \mathrm{c})$ Do you wish to comment whether you believe SCs are an integral part of the collaboration with BCHS and the ability of professionals/staff at $\mathrm{BCH}$ to advocate for their client/s.

Yes, absolutely integral and assumed that it is part of our role. We do secondary consults autonomously. Happens wherever convenient - over the phone, via email, in the corridor...we have 25 clients visit us in a row. SCs are reciprocal - it is not just between the lawyer and professional. Secondary consults help in later aspects of the case management. (Counsellor)

Yes, they are absolutely invaluable. Cheap way of gaining information. Cheaper and more efficient for the client. Prevents repetition for the client they don't have to keep going back over the story. Great that there is ongoing education gained via secondary referral process. Valuable to have co-location. Valuable to build the SC relationship - staff feel they can ask any question of the lawyer that they need to. They open up the door for referral and increased credibility - they build credibility of the lawyer and build trust. Facilitates building confidence in the workforce which in-turn positively impacts the client (safe place to disclose issues). (Social Worker)

'Secondary consultations are what provides the pathway of information and on processes for example what happens with filing of documents. They are of immense value to me as otherwise I would be confused. I can check in. I know when I am not sure I can just ask. The beauty is that we are not the experts but it helps us navigate the system for our clients- especially as many clients may not be ready to see a lawyer right away - you need to understand many of our clients if they have even had a lawyer at all it may not have been a good experience - it might have been a traumatic one. So we use secondary consultations to help clients who would otherwise never see a lawyer and help them ready themselves to see one if they need to by building up the trust. Most lawyers do not do a great job of respecting clients and to be honest I used the secondary consultation to test out the lawyer a number of times myself to see if I would be prepared to hand over my client. You see if a client is likely to be further harmed we have a duty of care. I have through the HJP come to see different type of lawyering which is truly effective. It gives me confidence, I know I can check in quickly which helps me help other clients and it provides a pathway - who is going to refer cold with such vulnerable clients so you need to know that secondary consultations are heavily linked into whether we will refer or not and if we don't have a good sense of the lawyer and how they will engage with our client we may not then refer. (In-depth Interview with health/allied health professional) 
The responses to question $4 \mathrm{c}$ ) below highlight the importance of SCs in terms of what makes professional refer clients to a lawyer and the type of lawyer that is critical to make a SC occur.

$4 \mathrm{c}$ What factors/tools, help or could help you in making effective referrals?

Secondary consults and an open door attitude helps me make effective referrals. If I'm unsure about a particular referral I ask [Lawyer] if referral is appropriate etc. [Lawyer] then does a conflict check. Open door is important as I already have a relationship with the client. When I refer to [Lawyer], the client feels confident that I'm referring to a lawyer of the service. Our clients already have lots of barriers to seeking assistance. Clients come here for many different reasons. (Nurse)

Fundamental and essential because they are where you start to get your information. Without them you would not know where to go. They are critical to creating confidence and promoting trust. You know you can go to [Lawyer] and you know she is receptive. You know you can approach her. She validates the SC process. She is approachable whereas traditionally lawyers don't come across that way. [Lawyer] is the right lawyer. The recruitment of the lawyer is essential to the partnership. The character of the lawyer is of utmost importance. The match needs to be right. (Counsellor)

In addition, the responses to question 4d) below highlight that SCs increase a sense of confidence and multi-disciplinary pathways particularly relevant for marginalised clients with complex needs and multiple problems.

$4 \mathrm{~d}$ ) What things assist you in making effective referrals?

Knowing that I can do secondary consults; [Lawyer] is very knowledgeable; open door policy of the lawyer. Gives me a great sense of reassurance. [Lawyer] covers those areas that need further explanation. (Nurse)

Discussion with the lawyer-moved on to SC and referral and then back to the lawyer again when the client became a client of the lawyer. I assisted the client in consultations with the lawyer as did the GP, the Social Worker and Alcohol and Drug Worker. (Counsellor)

The value of SCs was noted in interviews with management/ relationship holders:

Talking about the multitude of legislation and how our service can interpret it for the client. Bringing people who might otherwise be excluded back to the table.

SCs according to participants were critical in raising awareness. Without ease of access and continuity the clients might otherwise have had their human rights and legal issues escalate, compounding human rights intrusions. The aggregated data revealed that $91 \%$ of those clients had at least three legal problems and $71 \%$ of these clients reported poor previous experiences of a lawyer had been a deterrent in them seeking help. Ninety-one $\%$ of clients interviewed would not have consulted a lawyer for their legal issue/s but for 
the HJP. Similarly, the aggregated quantitative and qualitative data from the health and allied health professionals revealed that they too had either poor previous experiences of lawyers or the adversarial system until the HJP and that this increased their reticence to refer or use lawyers. SC were consistently identified as critical over the life of the project in enhancing positive perceptions of lawyers and their later decisions to refer clients.

Clients are responsive. Not always the best experience with lawyers at court. Many have encountered legal issues at very early age. The experience here would positively challenge the clients' perceptions of the legal system/ lawyer. As far as I'm concerned as a professional. I try to use it as much as I can. I try to increase the confidence in the client when engaging the lawyer. The mantra that was bantered around by the lawyer was that the door is always open. Very easy. Bendigo Community Health Service is seen as a trusted organization. We have the holistic view for the clients. It would be disastrous if we lose the service now because we would lose the goodwill of the clients. Consistency and continuity are very important with this cohort of clients. How else are they going to know if we don't give the clients a voice. Our client's issues need to be addressed, sooner the better, it is important as it help us identify the issue. We have families walk through the door looking for assistance. We are called community health because we are here for our community. Family/parents relieved that they have connected with the lawyer if they are introduced and encouraged to a lawyer tends to deal with the stress at home. (In-depth Interview with health/allied health professional)

Interestingly, an analysis of the responses to questions about SCs sees the proxies suggestive of having an impact that have been developed, namely: Collaboration; Capacity; Engagement; Voice; Empowerment; and Improved Advocacy. This is illustrated by one of many case studies emerging from the two snapshots:

Client I referred after an SC stated that she has been able to feel comfortable talking with the lawyer and that if she did not have access to a lawyer then she would not have any access to her child and would not have seen the child again during his childhood years. Invaluable for this client was understanding that she did have rights and that there is a process that can be followed rather than just thinking that all is hopeless and that she started to believe what the child protection [services] were telling her - that she is a really poor mother.

The need for systemic reform has also been identified in SCs. For example, through SC in 2015, it emerged that the Department of Human Services had not been providing clients with timeframes within which they were to lodge their requests for a review in relation to their child contact. The health service in collaboration with the legal service (through the HJP) have since written to the Department requesting that timelines routinely be included in letters to parents. At the conclusion of the field research in June 2016 most of the non-legal professional participants noted that in future there would be more opportunities for future collaboration on systemic issues due to an increase in positive relationships partly due to the experiences gained through LSC. 
As this project occurred over a series of weeklong snapshots (eight months apart) data was able to be gathered in the short, medium and longer term. Accordingly, some comparative data and progressions were gauged. It was reiterated throughout the research that the usefulness and reach of SC led to an increase in confidence in SC as a result of 'effective' co-location' and 'opportunistic' access to a lawyer for SC 'at critical times' or for 'a client when in crisis'. It seems from the empirical research so far that Tobin Tyler's comments resonate in Australia:

Access to lawyers, armed with knowledge about eligibility requirements for public benefits, educational rights of children with special needs, and tenants' rights to safe housing, can help dismantle some of those seemingly insurmountable barriers. Lawyers can also work with physicians (health and allied health) to help them advocate more effectively for patients by helping them to craft more persuasive letters to schools or government agencies about a child's needs. (Tobin Tyler, 2008, p. 5)

\section{Conclusion}

People who experience disadvantage or who are vulnerable are most likely to have their legal rights trampled on or ignored. Without knowing legal rights or avenues exist and with often heavy caseloads, ways in which the professionals who are likely to see people who are currently excluded that are quick, accessible and timely need to be found. Secondary consultations to help at critical moments is one way of reaching more people in need of advice about their legal position and rights and also of skilling up professionals to give them confidence to provide information, assist navigation of a complex legal system and build their capacity and confidence to refer to a community lawyer when appropriate.

Findings from the author's recent research suggest that good reciprocal relationships and experience with a particular practitioner or service through SC can be critical in enabling effective referrals and building the capacity of the non-lawyer to advocate and assist clients. Given the barriers to access to legal help (Coumarelos et al., 2012) the author contends that, if clients can gain legal assistance through their trusted professional intermediary by SCs, then professionals being supported by lawyers raises awareness of the gamut of issues that are legal in nature, thus expanding the opportunities for clients and workers to engage more directly and immediately on legal issues. It also extends the reach of currently stretched legal assistance services through the ability of 'trusted intermediaries' as the SC provides information that non-legal professionals can use not just for one client but for others.

The evidence from LCCLC, Consumer Action, The Legal Services Board study (the latter for which the author has been advising on only) and the Bendigo Health Justice Project have all suggested that SCs increase the capacity and confidence of non-legal professionals to use legal solutions. It works to build understandings across different disciplines, improves the ability to identify legal problems capable of a solution, improves client referral pathways and for the lawyers enables them to better understand client contexts through working with different multi- disciplinary professionals. If done well, SC can build bridges, remove barriers between professionals and enhance their capacity to respond to complex client problems and build a relationship of trust that can transcend existing barriers to seeking legal help. This means the invisible and disadvantaged $86 \%$ 
of clients who were not gaining legal help previously may now have pathways to alleviate their problems using SC.

As the data discussed in this article demonstrates SCs enable professionals to quickly check in with a lawyer to identify and rectify how poor treatment can be addressed under the laws and regulation which govern so many facets of human life. The author contends that legal SCs which, until now, have not been valued, considered, counted, researched or evaluated are critical innovations to ensure those who need help are reached. The traditional focus in Australia and abroad in legal service delivery, be it by private lawyers or through salaried legal assistance, has often been limited to purely legal advice, information and representation. This model assumes that clients and their trusted intermediaries' know enough about their legal rights, have money or access to lawyers to make an appointment.

The approach of having lawyers working collaboratively with non-lawyers by providing SC, although it has challenges, is demonstrating effectiveness in targeting those who are currently excluded from gaining legal assistance. It is also revealing improvements to client and worker engagement with an array of legal problems and proactive solutions. The research is revealing potentially downstream benefits extending the reach to a greater number of people in need. 


\section{References}

\section{Legal}

Victorian Charter of Human Rights and Responsibilities 2006 Act (Vic). Available:

Other

http://www.austlii.edu.au/au/legis/vic/consol_act/cohrara2006433/

Balmer, N.J., Buck, A., Patel, A., Denvir, C., \& Pleasence, P. (2010). Knowledge, capability and the experience of rights problems. Retrieved from

http://www.lawforlife.org.uk/wp-content/uploads/2010/05/knowledge-capability-andthe-experience-of-rights-problems-Isrc-may-2010-255.pdf

Balmer, N.J., Pleasence, P., Buck, A., \& Walker, H. (2006). Worried sick: the experience of debt problems and their relationship with health, illness and disability. Social Policy and Administration, 5(1), 39-51. http://dx.doi.org/10.1017/S147474640500271X

Better Health Channel. (2011). Community health centres. [Fact sheet]. Department of Health \& Human Services, State Government of Victoria. Retrieved from https://www.betterhealth.vic.gov.au/health/healthyliving/community-health-centres

Buck, A., Balmer, N.J., \& Pleasence, P. (2005). Social exclusion and civil law: experience of civil justice problems among vulnerable groups. Social Policy and Administration, 39(3), 302-322. http://dx.doi.org/10.1111/j.14679515.2005.00441.x

Buck, A. \& Curran, L. (2009). Delivery of advice to marginalised and vulnerable groups: the need for innovative approaches. Public space: The Journal of Law and Social Justice, 3(7), 1-29. Retrieved from http://epress.lib.uts.edu.au/journals/ index.php/ publicspace/article/view/1232/1239

Buck A., Pleasence, P., \& Balmer, N. (2008). Do citizens know how to deal with legal issues? Some empirical insights. Journal of Social Policy, 37(4), 661-681. http://dx.doi.org/10.1017/s0047279408002262

CSDH (2008) Closing the gap in a generation: Health equity through action on the social determinants of health. Final Report of the Commission on Social Determinants of Health. Retrieved from World Health Organization website: http://apps.who.int/iris/bitstream/10665/43943/1/9789241563703_eng.pdf

Coumarelos, C., MacCourt, D., People, J., McDonald, H.M., Wei, Z., Iriana, R., \& Ramsey, S. (2012). Access to justice and legal needs: legal Australia wide survey - legal need in Australia. Retrieved from Law and Justice Foundation of New South Wales website: http://www.lawfoundation.net.au/ljf/site/templates/

LAW_AUS/\$file/LAW_Survey_Australia.pdf

Curran, L., Willcox, T., \& Williams J. (2016a). Evaluating Consumer Action's Worker Advice Service, June 2016, https://papers.ssrn.com/sol3/papers.cfm?abstract id=2835377

Curran, L., Wong C., \& Ball, S. (2016b). Health-Justice Partnerships Development Report 2016. http://www.Isbc.vic.gov.au/documents/ReportHealth Justice Partnership Develo pment-2016.PDF

Curran, L. (2016c). Health Justice Partnerships (HJP): Working Ethically to Reach Those in Most Need of Legal and Medical Support \& to Improve Outcomes - Research Evidence, a Seminar for City, University of London (Law School) 13 September, 2016, London (Presentation Slides) (September 13, 2016). Available at SSRN: https://ssrn.com/abstract=2841379 or http://dx.doi.org/10.2139/ssrn.2841379 
Curran, L. (2007). Ensuring justice and enhancing human rights: a report on improving legal aid service delivery to reach vulnerable and disadvantaged people. La Trobe University and the Victorian Law Foundation. Retrieved from SSRN Electronic Journal website: http://dx.doi.org/10.2139/ssrn.2395075

Curran, L. \& Noone, M. (2007). The challenge of defining unmet legal need. Journal of Law and Social Policy, 21 (Spring), 63-89. Retrieved from http://digitalcommons.osgoode.yorku.ca/jlsp/vol21/iss1/4

Curran, L. (2013). Legal review: not all in the statistics. [Article]. Law Institute Journal, July, 36-39.

Curran, L. (2015). Final evaluation report on the 'Why didn't you ask?' Family Violence Project of Loddon Campaspe Community Legal Community Legal Workshop, Australian National University (May). Retrieved from http://lcclc.org.au/wpcontent/uploads/2015/05/Executive-Summary-Evaluation-WDYA-15-May-2015.pdf

Green, A., Betancourt, J., \& Carillo, J. (2002). Integrating social factors into crosscultural medical education. Academic Medicine, 77(3), 193-197. Retrieved from http://journals.Iww.com/academicmedicine/Fulltext/2002/03000/ Integrating_Social_Factors_into_Cross_cultural.3.aspx

Griffiths-Baker, J. (2015). The good, the bad and the ugly: Lawyers in film and fiction. [Video file]. Nottingham Trent University Inaugural Dean's Lecture, June 15. Retrieved from https://www.ntu.ac.uk/nls/about/the_dean/index.html

Gyorki, L. (2014). Breaking down the silos: overcoming the practical and ethical barriers of integrating legal assistance into a healthcare setting. Retrieved from Winston Churchill Memorial Trust website: https://www.churchilltrust.com.au/ media/fellows/Breaking_down_the_silos_L_Gyorki_2013.pdf

Healthy People 2020. (2014). Leading health indicators progress update (March). US Department of Health and Human Services. Retrieved from http://www.healthypeople.gov/2020/leading-health-indicators/Healthy-People2020-Leading-Health-Indicators\%3A-Progress-Update

Loddon Campaspe Community Legal Community. (2015). LCCLC Collaborative Survey Tool Health Survey 2015. Unpublished.

Moorhead, R., Robinson, M., \& Matrix Research and Consultancy. (2006). A trouble shared: Legal problems clusters in solicitors' and advice agencies. DCA research series 8/2006. Department of Constitutional Affairs, London. Retrieved from http://www.law.cf.ac.uk/research/pubs/repository/1592.pdf

Naitove, B. (1982). Medicolegal education and the crisis of inter-professional relations. American Journal of Law and Medicine, 8, 293.

Neville, B. \& Dalmau, T. (2008). Intervening for cultural change in organisations. Flat Chat Press, Northern Melbourne Institute of TAFE, Greensborough, Victoria, 13-14.

Noble, P. (2012). Advocacy-health alliances: Better health through medical-legal partnership. Loddon Campaspe Community Legal Centre and The Clayton Utz Foundation. Retrieved from https://advocacyhealthalliances.files.wordpress.com/ 2012/08/aha-report_general1.pdf

Noone, M. \& Digney, K. (2010). "It's hard to open up to strangers" - Improving access to justice: the key features of an integrated legal services delivery model. La Trobe University Rights and Justice Program Research Report, September 30. Retrieved from SSRN Electronic Journal website: http://papers.ssrn.com/ sol3/papers.cfm?abstract_id=1799648

Norton, M. (1971). Development of an interdisciplinary program of instruction in medicine and law, Journal of Medical Education, 46(5), 405-11. 
Peter MacCallum OnTrac (n.d.). [website]. Peter MacCallum Cancer Centre, Melbourne. Retrieved from http://www1.petermac.org/ontrac/ statewide_services.htm

Productivity Commission. (2014) Access to justice arrangements: Draft report (Overview). Australian Government, Canberra. Retrieved from http://www.pc.gov.au/inquiries/completed/access-justice/draft

Roberts, T. \& Currie, J. (2012). PBLO at SickKids: A Phase II evaluation of the medical legal partnership between Pro Bono Law Ontario and SickKids Hospital Toronto, Final Report. Focus Consultants, Victoria, Canada. Retrieved from http://www.probono.net/va/search/item.451249

Schwarz, M., Allison, F., \& Cunneen, C. (2013). The civil and family law needs of Indigenous people in Victoria. Retrieved from James Cook University website https://www.jcu.edu.au/_data/assets/pdf_file/0011/121889/jcu_131180.pdf

Sheridan, S.M., Welch, M., \& Orme, S.F. (1996). Is consultation effective: A review of outcome research. Educational Psychology Publications and Papers 57. Retrieved from http://digitalcommons.unl.edu/edpsychpapers/57

Spectrum. (2016). Secondary Consultation. [web page]. Retrieved from http://www.spectrumbpd.com.au/pages/spectrum-programs/secondaryconsultation.php

Tobin Tyler, E. (2008). Allies not adversaries: Teaching collaboration to the next generation of doctors and lawyers to address social inequality. Roger Williams University School of Law Faculty Papers. Paper 17. Retrieved from http://lsr.nellco.org/rwu_fp/17

Trubek, L. \& Farnham, J. (2000). Social justice collaboratives: multi-disciplinary practices for people. Clinical Law Review, 7, 227. Retrieved from https://law.wisc.edu/m/mtbyz/social_justice_collab.rtf

World Health Organisation (WHO) and Commission on Social Determinants of Health (2008). Closing the gap in a generation: Health equity through action on social determinants of health. Retrieved from World Health Organisation website: http://whqlibdoc.who.int/publications/2008/9789241563703_eng.pdf?ua=1 


\section{Biographical Notes}

Dr Liz Curran is a Senior Lecturer in the Masters of Legal Practice Program, ANU College of Law. She has worked as a solicitor in private practice and in community legal services and was Lecturer/Clinical Supervising Solicitor for La Trobe University. She continues to engage in direct service delivery through a secondment to the Consumer Action Law Centre in Melbourne. Her research interests include access to justice, measurement of outcomes in legal assistance services, integrated service delivery, Health Justice Partnerships and human rights. Liz has also worked overseas engaging in community development, capacity building and advocacy in numerous disadvantaged communities

\section{Acknowledgements}

The author thanks the ANU Research Support Team and Human Ethics Committee, Consumer Action Law Centre, ARC Justice Bendigo, Bendigo Community Health Service, Banyule Community Health, the Legal Services Board and Commissioner of Victoria, Gerard Brody, Tom Wilcox, Jill Williams, Sue Ball, Peter Noble \& Dr Robert Southgate and all research participants. 